\title{
Proposal of assistive application for educational lecture with iBeacon
}

\author{
Hayato Takahashi $^{\mathrm{a}}$, Yuhki Kitazono ${ }^{\mathrm{a} *}$ \\ ${ }^{a}$ National Institute of Technology, Kitakyushu College,5-20-1 Shii, Kokuraminami-ku, Kitakyushu-city, \\ Fukuoka 802-0985, Japan \\ *Corresponding Author: kitazono@kct.ac.jp
}

\begin{abstract}
In this system, we propose an assistive application for educational lecture. This system is composed of two main technologies; iBeacon and Multipeer Connectivity. iBeacon is a region observing technology with Bluetooth. Multipeer connectivity is a framework to form a mesh network. By using both of the technologies, the system can manage attendance of students and distribute handouts through the system in educational lecture.
\end{abstract}

Keywords: iBeacon, Multipeer Connectivity.

\section{Introduction}

In many university lectures, handouts like resume are printed out and handed out to students. However, owing to print cost, there are some cases that not enough number of handouts are prepared, or handouts including color figures are printed in monochrome. Then, some students attending the lecture couldn't get the handouts, or color figures couldn't be read. Most university lecturers make handouts which is handed out in their lecture on computer, using software such as Power Point. Thereby, they have that handouts document data in electronic document data. Some lecturers hand out their handouts in electronic document data through website. For instance, National Institute of Technology, Kitakyushu college is using a website; Webclass ${ }^{(1)}$, and their students can browse and download documents that lecturers uploaded, by accessing and logging in to the site. Some lecturers use this system and hand out their lecture document through Webclass, however, in fact, most of the lecturers in the school don't use this system, and hand out their documents by printing out, not in electronic data. The fact supposed to be the cause of that, it may be a burden that the lecturer has to access to the administration site and upload their documents every time they hand out, and that students have to $\log$ in to the site to only download the documents they would like to download. Owing to such burdens, smooth distributing of electronic document data has never been done ever.

Besides, attendance management is a big burden next to handing out. Currently, attendance management is done in several ways. In those, the common way is roll call method and attendance card submitting method. Roll call method is that the lecturer calls the name of each students and regard the students who responded the call as being attendant. Attendance card submitting method is that a card is distributed at a lecture, and students write his name and student id number on the card. In the end of the lecture, students submit the card to the lecturer, and the lecturer aggregates the attendance of students after the lecture. Each method confirms the attendance of students manually, so it takes labor. Not only it's taking labor, but also wasting time of lecture in call roll method, and wasting lecturer's time out of lecture in attendance card method. It's very inefficient, and it should be improved.

Therefore, we suggest a system which can manage student's attendances automatically and reduce time and effort for printing and distributing the handouts.

This system detects entrance and exit of students automatically with iBeacon: region 
observing technology with Bluetooth Low Energy. In addition to region observing, the system constructs a mesh network to distributing handouts from lecturer's device to students' devices, with framework "Multipeer Connectivity". By using this system, we can detect students who entered or exited the lecture room.

\section{Base Technology}

\section{1 iBeacon}

This system gets the number of students and who is in the lecture room with region observing technology; iBeacon. iBeacon is a region observing and proximity detecting technology with Bluetooth Low Energy of iOS devices suggested by Apple.Inc ${ }^{(2)}$. In iBeacon system, transmission terminal is called "Peripheral", and reception terminal is called "Central". Using iBeacon, background region observing is available without launching any application on smartphone, and if the device entered to a region, the system sends a notification to the device.

In this region observing technology, Central terminal receives a signal from Peripheral terminal. The state whether the Central terminal is in a region or not, is detected by whether the terminal receives a signal from Peripheral terminal. We show a conceptual diagram of region observing with iBeacon in Fig.1.In addition to detecting in or out region, it can detect approximate distance from Peripheral terminal in four statuses; "Immediate", "Near", "Far", "Unknown". The distance is detected by RSSI(Received Signal Strength Indication).

iBeacon in itself is a just regulation for submitting beacon information with Advertising Packet defined by Bluetooth4.0. The beacon information is consisted of Proximity UUID of 16bytes, Major Value of 2 bytes, Minor Value of 2 bytes, and TX Power of 1 byte. Proximity UUID, Major Value, and Minor Value are an identifier for signal and set in any value by developer. TX Power is to be set an estimate value of beacon signal strength at $1 \mathrm{~m}$ distance point from Peripheral terminal. The Major value is used to identify signals which have same Proximity UUID. The

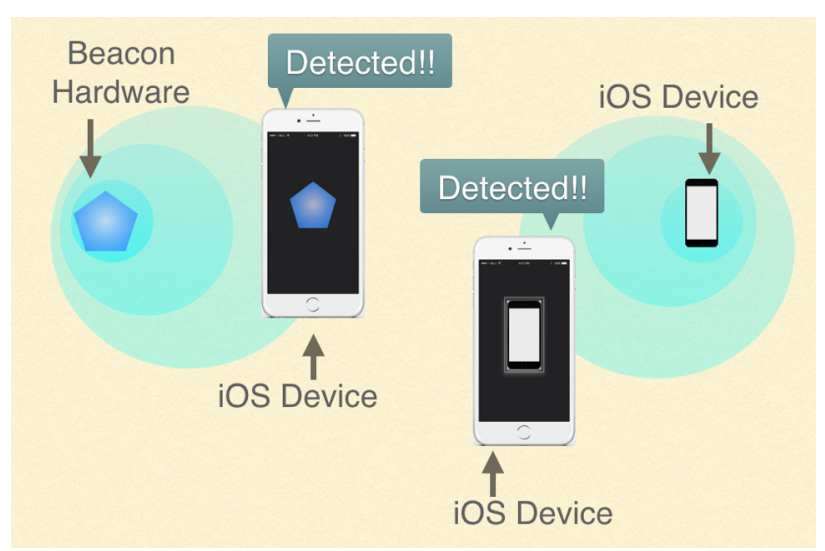

Fig. 1. Conceptual diagram of region observing with iBeacon.

Minor value is used to identify signals which have same Proximity UUID and same Major value. Setting Proximity UUID is required, but setting Major value and Minor value is optional. In this system, iBeacon is used to detect entrance and exit to lecture room.

iBeacon has a feature that the region observing could be operated with Bluetooth Low Energy in background state of application.

The system is intended to detect attendance of students automatically, so we adopt iBeacon system for attendance detection. Students have to only receive a notification from the system and launch application, then their attendance is accepted.

\subsection{Multipeer Connectivity Framework}

This system uses framework "Multipeer Connectivity" which can set up peer to peer connection with Bluetooth to broadcast document data from lecturer to students.

Multipeer Connectivity is a framework for iOS provided by Apple.Inc ${ }^{(3)}$. It can make up peer to peer connection between iOS devises nearby. In this framework, there are three connection method; 1. connection with Wi-Fi between devices which are in LAN, 2. connection with Wi-Fi between peer, 3. connection with Bluetooth between peer. In conventional connection method, the devices which is to connect is required to be in same LAN. In spite that, by using Multipeer Connectivity framework, devices can connect with Bluetooth or Wi-Fi directly, so the system doesn't require to be in same LAN. 


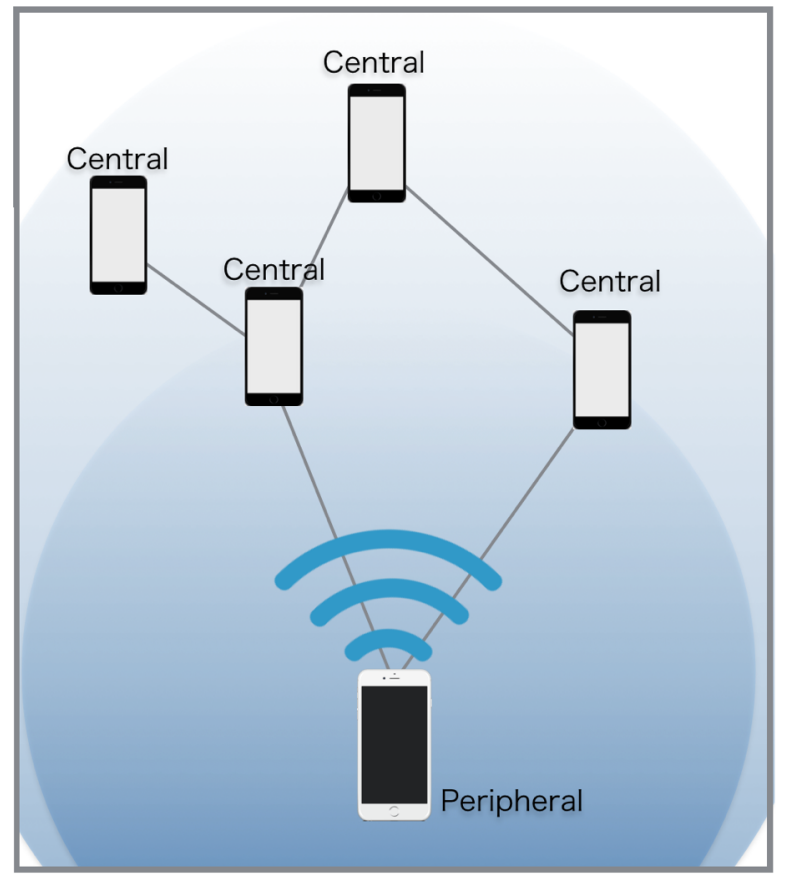

Fig. 2. Region and iBeacon terminal in a lecture room.

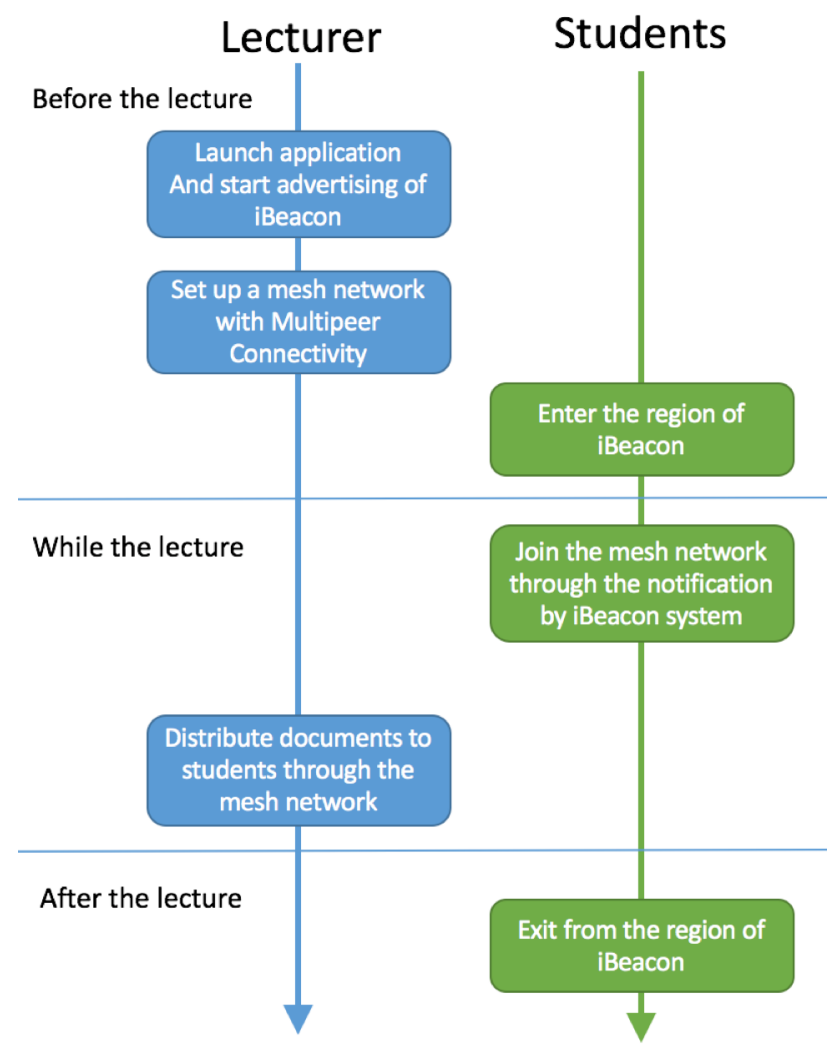

Fig. 3. Operating procedure of the system.
This system is intended to distribute handouts for students in lecture room. By adopting this method, the system can distribute documents directly without certain internet connection.

\subsection{Cooperation of iBeacon and Multipeer Connectivity}

We intended the system to be able to join the mesh network smoothly by combining Multipeer Connectivity framework with iBeacon. Since joining mesh network with Multipeer Connectivity needs to launch its application, the system send notification to user if the system detected that the user entered the region where a mesh network is. There is a shortcut to launch the application, so user can notice and join the mesh network. With this notification, it can be prevented that the user isn't aware of network and doesn't join it.

\section{Attendance management with region observing by iBeacon}

In this section we will describe about operation of attendance management in a lecture.

At first, to enable region observing, set the lecturer's device as a Peripheral terminal of iBeacon. At launch of the application, set UUID value to identification value of school, Major value to identification value of the class, Minor value to identification value of the day. After launching Peripheral application on lecturer's device, the lecture room become the range of region observing, due to range of Bluetooth signal. The conceptual diagram of iBeacon region and iBeacon terminals in a lecture room is shown in Fig.2. If a student entered the lecture room, his device catches the iBeacon signal from Peripheral, then he can send attendance data to lecturer by launching application from shortcut on notification. The operating procedure of the system shown in Fig.3.

\section{Usability Test}

In order to confirm the utility of the system, we carried out usability test. In this test, we reproduced the flow of use of the application in actual lecture, such as shown in Fig. 3. Two terminals are prepared, one is to operate as a 
lecturer side of the application and the other is the student side of the application. First, lecturer side launches the application, and start advertising as Peripheral side of iBeacon. And then it launches a Multipeer Connectivity session as the advertiser of Multipeer Connectivity, to wait for the participation of the student side. Then students, upon entering the detection area of the teacher side iBeacon, a notification is sent. Student side start the application when it received a notification, to participate in the Multipeer Connectivity session which is prepared by lecturer. Up to this point is a flow of up to handouts distribution start. After students and lecturer have completed the above steps, the lecturer can distribute the handouts. And after distributing, students browse the documents in this application. In this usability test, we performed the procedures both of student side and lecturer side stated above.

\section{Result and consideration}

The images of the experiment are shown in Fig. 4 - 7. Fig. 4 shows an iBeacon setup screen of the application. By pressing the "Set up Lecture" button in the middle of the screen left, lecturer's terminal can be operated as Peripheral of iBeacon. When the student entered the detection area of iBeacon while the lecturer was running the application as Peripheral, notification was sent to the student's terminal, as shown in Fig. 5. Students start the app by tapping the notification, and then make attendance processing by tapping "Join Lecture" button in the middle of the screen. And after having completed the iBeacon process by both professors and students, they press the "Multipeer Mode" button and the screen transitions to the screen shown in Fig. 6. And then lecturer presses the "Connect as Lecturer" button, to perform Advertise as Advertiser side of Multipeer Connectivity. By pressing "Connect as Student" button, student browses Advertiser as Browser side of Multipeer Connectivity. Browsing screen is shown in Fi.7. After connecting the session by Multipeer Connectivity, lecturer can send images stored in the camera roll from button "Send Images".

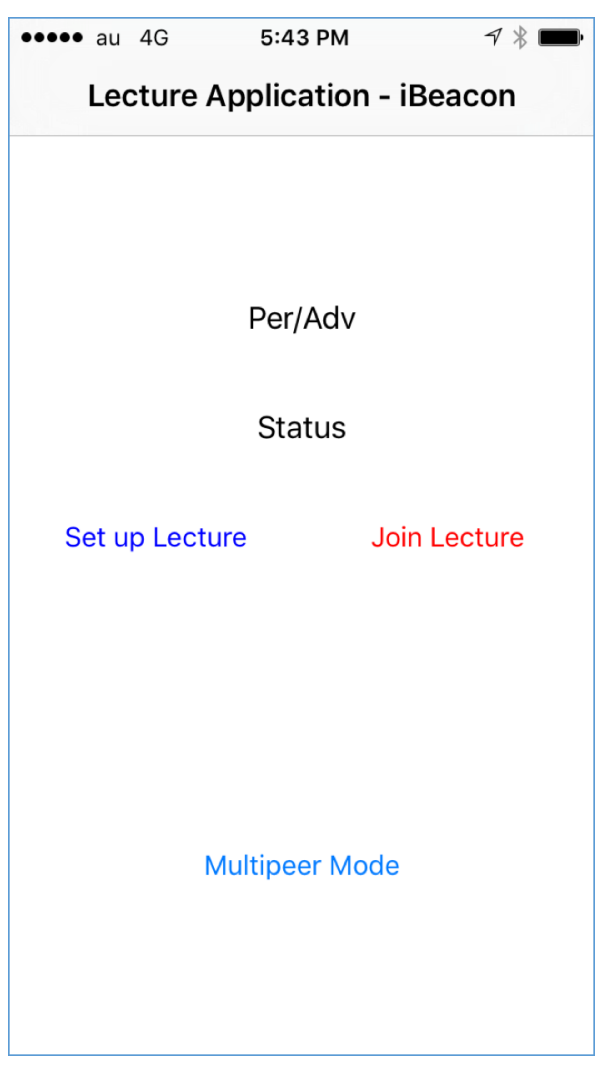

Fig. 4. iBeacon setup screen.

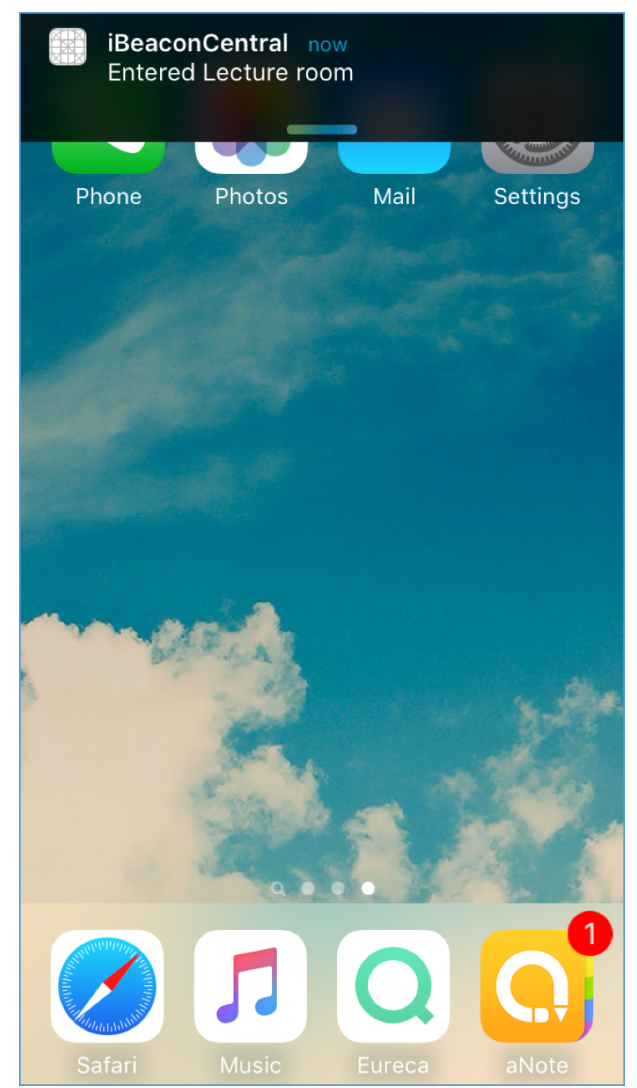

Fig. 5. Receiving local notification. 


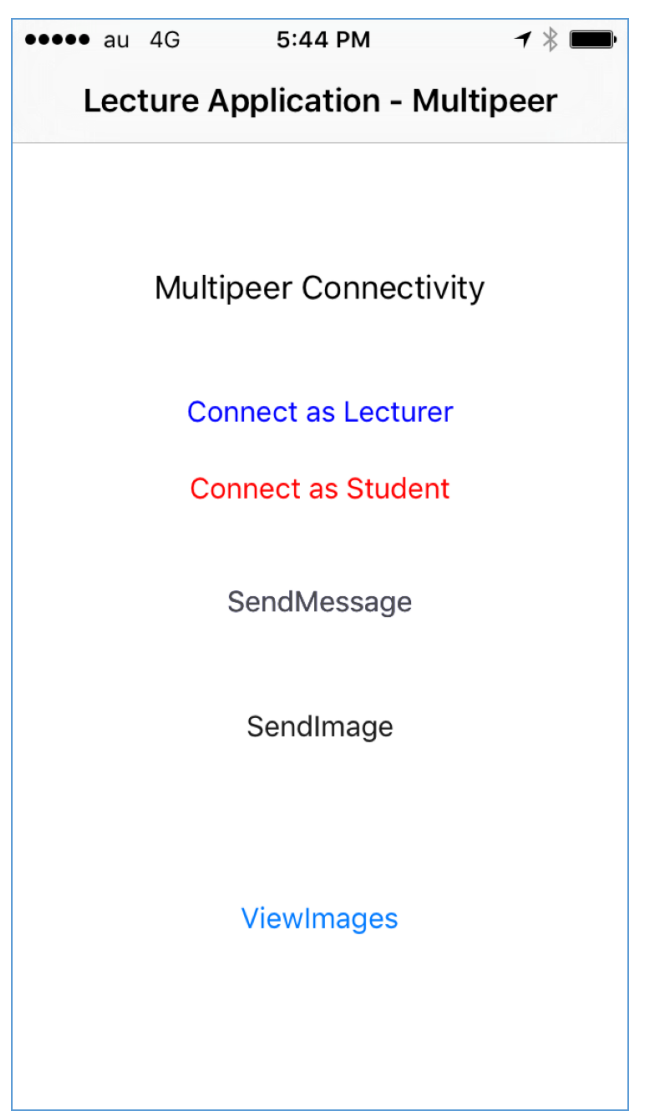

Fig. 6. Multipeer Connectivity setup screen.

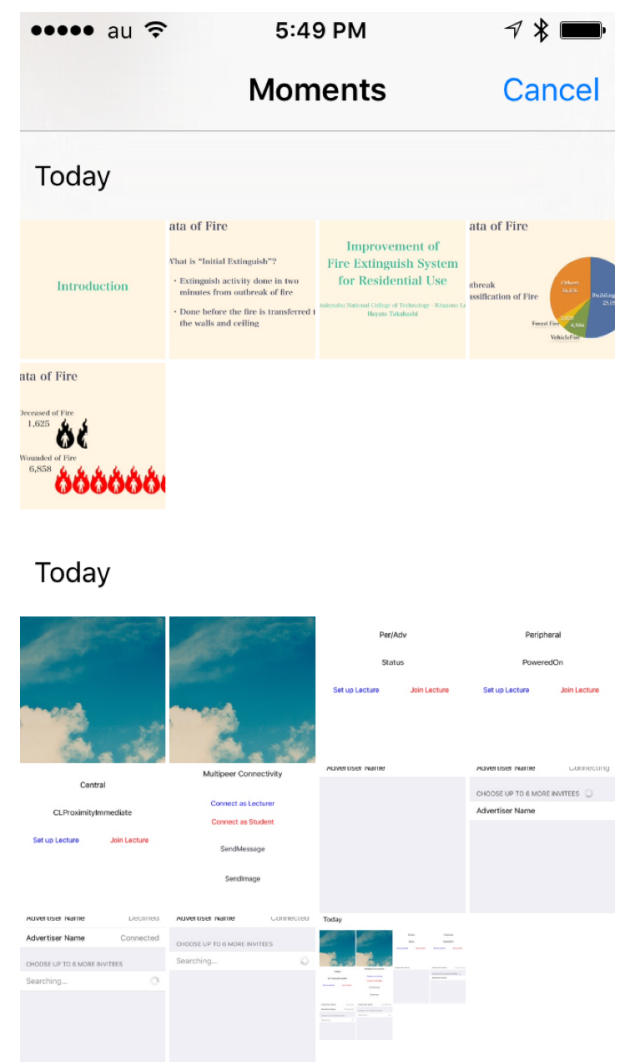

Fig. 7. Photo select screen.
We conducted the test stated above in actual application we made. In that case, the detection by iBeacon, and distribution of handouts document data by Multipeer Connectivity have been done properly. It was possible to confirm the utility of the system. The system because it can perform a file transmission in locally using Bluetooth or Wi$\mathrm{Fi}$, does not require an Internet connection at all steps. Therefore, the system seems to have advantages over such application using network server for distributing documents. Moreover, since it is possible to start the application from the notification sent by application, it is also greatly reduced effort to app used.

\section{Future Tasks}

The object of the present system is that possible data which can be transmitted through this system is only the image. This is due to that the Multipeer Connectivity's supported format is presently only the image format. The lecturer is apt to make up their lecture document with Powerpoint. Since it has a function to export the document in images, the system would narrowly suffice the needs for transmission. Nevertheless, it is desirable to correspond to the PDF format which is most popular format for document. In addition, because test was performed in a small number of terminals, it is necessary to verify behavior and reliability when the terminal number becomes so many.

\section{References}

(1) National Institute of Technology Kitakyushu College, Webclass: https://webclass.edu.kct.ac.jp

(2) Apple, iBeacon for Developers: https://developer.apple.com/ibeacon/

(3) Apple, Multipeer Connectivity Framework Reference:

https://developer.apple.com/library/ios/docum entation/MultipeerConnectivity/Reference/M ultipeerConnectivityFramework/ 